\title{
Development and application of a duplex QPCR for river water samples to monitor the myxozoan parasite Parvicapsula minibicornis
}

\author{
Sascha L. Hallett*, Jerri L. Bartholomew \\ Department of Microbiology, 220 Nash Hall, Oregon State University, Corvallis, Oregon 97331, USA
}

\begin{abstract}
A duplex quantitative polymerase chain reaction (QPCR) assay was developed to simultaneously quantify the myxozoan parasite Parvicapsula minibicornis in river water samples and detect inhibition, which may compromise recognition of the target organism. The assay combines a TaqMan MGB probe specific to the nuclear small subunit ribosomal RNA gene of P. minibicornis and a commercial TaqMan Exogenous Internal Positive Control. P. minibicornis is endemic to freshwaters of the Pacific Northwest of North America and contributes to reduced fish health in Klamath River (Oregon/California) salmonids. The prevalence of $P$. minibicornis in these fish can reach $100 \%$, and infection can result in glomerulonephritis and impaired kidney function. To better understand the temporal and spatial occurrence of this parasite in the Klamath River basin, water samples were taken from 7 mainstem sites and 5 tributaries along the $400 \mathrm{~km}$ river from March through September 2006. The samples were filtered, and the captured DNA was extracted and tested for the presence of P. minibicornis with the duplex QPCR assay. The parasite was present throughout the river over the entire sampling period, but its distribution and abundance varied spatially and temporally by over 2 orders of magnitude. Spore densities were lowest in March (spring) and peaked in June/July (summer) when site variance was also greatest. Inhibition levels also varied. The assay is able to detect 1 actinospore (the life cycle stage infective to fish) in 11 of water and offers an alternative to sampling fish to monitor this pathogen and develop management options.
\end{abstract}

KEY WORDS: Parvicapsula minibicornis ' River water samples · Quantitative PCR · Klamath River · Salmonids $\cdot$ Myxozoa $\cdot$ Monitoring program

Resale or republication not permitted without written consent of the publisher

\section{INTRODUCTION}

Concerns about the effects of disease on salmonid populations in the Klamath River basin have increased over the past decade. The Klamath River extends for over $400 \mathrm{~km}$ from south-central Oregon to the Pacific Ocean in northern California, USA, and native populations of coho salmon Oncorhynchus kisutch have been identified as an evolutionarily significant unit of a species and listed as threatened since 1997 (National Research Council 2004). In addition, low numbers of Chinook salmon $O$. tshawytscha have resulted in severe harvest restrictions, which led to the declaration of a commercial fishery failure in 2006. A mass die-off of returning adult salmon in 2002 and the con- tinuing high yearly loss of juvenile fish have prompted efforts to understand disease epidemiology in this system.

The myxozoan parasites Ceratomyxa shasta and Parvicapsula minibicornis are recognized as adversely affecting fish health in the Klamath River (Nichols \& Foott 2006, Nichols \& True 2007). Both pathogens share their vertebrate (salmonid fish) and invertebrate (polychaete) hosts (Bartholomew et al. 1997, 2006), and their geographic distributions overlap (Bartholomew et al. 2007). Ceratomyxa shasta has been implicated as a significant source of out-migrant mortality in juvenile fall Chinook salmon (Foott et al. 2004a, Stocking et al. 2006) and causes abdominal distension from excessive ascite production, lethargy, and inappetence and can become sys- 
temic (Conrad \& Decew 1966, Schafer 1968, Bartholomew et al. 1989). Less information exists regarding the impacts of $P$. minibicornis on Klamath River salmonids. It has been present in the Klamath River since at least the early 1990s (Foott et al. 2004b), and prevalence can reach $100 \%$ in juvenile Chinook salmon during their summer seaward migration (Nichols \& True 2007) and greater than $90 \%$ in returning adult Chinook and coho salmon and steelhead (Bartholomew et al. 2007). The parasite can cause kidney damage (glomerular nephritis) and hypoproteinema and may affect osmoregulation during freshwater/saltwater transition. C. shasta and P. minibicornis commonly co-occur, and infections with both parasites may have synergistic effects (Nichols et al. 2007).

Pathogen monitoring (spatial and temporal distribution and abundance) is an integral part of developing management strategies to reduce the impact of disease on free-ranging and wild fish populations. Analysis of water samples using quantitative (or real-time) PCR (QPCR) is a relatively new method that allows both detection and quantification of specific parasites (e.g. Audemard et al. 2004, McBeath et al. 2006) and may replace the traditional use of caged susceptible hosts (Hallett \& Bartholomew 2006). Two molecular assays (1 PCR and 1 QPCR) have been developed to detect Parvicapsula minibicornis DNA in fish tissue (StHilaire et al. 2002, True et al. 2009). QPCR offers the best approach for screening water samples; however, since development of the assay, multiple strains of $P$. minibicornis have been documented from different hosts and geographic locations (Atkinson et al. 2007) and the region of the small subunit ribosomal RNA (ssrRNA) gene targeted by the original QPCR is not conserved among all isolates. This, coupled with the specific processing requirements of water samples, impelled us to redesign the primers and QPCR methodology. Incorporation of an internal positive control (IPC) in an assay to assess for inhibition enables distinction between true (no parasite DNA present) and false (parasite DNA present but inhibitors have interfered with the reaction) negatives. This study describes the development of a duplex QPCR to both detect $P$. minibicornis and assess inhibition in river water samples and its field application to document the distribution and abundance of the parasite in the Klamath River in 2006.

\section{MATERIALS AND METHODS}

\section{Duplex QPCR assay design. Primer and probe selec-} tion: Parvicapsula minibicornis (Pm): The mid-region of the nuclear 18S ssrRNA gene was targeted to maximize variation between myxozoan species and to address the variation detected among $P$. minibicornis isolates from different hosts and locations. A Clustal W alignment was constructed to highlight regions conserved among the P. minibicornis isolates (6, plus AF201375 and DQ231038) but which varied from other species within the genus ( $P$. pseudobranchicola AY308481, P. asymmetrica AY584191, and P. unicornis AY584190). A TaqMan minor groove binding (MGB) probe and primers specific for $\mathrm{Pm}$ were manually designed with Applied Biosystems (ABI) Primer Express software version 2.0 following ABI guidelines and those in Bustin (2004). The FAM-labeled probe ('Pm-duplex- $\mathrm{P}$ ') is: 5' TGT CCA CCT AGT AAG GC; the forward primer ('Pm-duplex-F'): 5' AAT AGT TGT TTG TCG TGC ACT CTG T; and the reverse primer ('Pm-duplex-R'): 5' CCG ATA GGC TAT CCA GTA CCT AGT AAG which produce an amplicon of $72 \mathrm{nt}$. The probe was ordered from ABI and the primers from Invitrogen. An NCBI nucleotide BLAST search was conducted with each primer and probe sequence to confirm specificity to $P m$. The primers were checked for lack of dimerization using the ABI software. To confirm amplification of a fragment of expected size, the primers were used in a regular PCR with known positive samples, and the products were visualized on a $2 \%$ agarose gel.

Inhibition indicator: The commercially available TaqMan Exogenous IPC Reagents kit (ABI) was used to test for inhibition. This includes a VIC-labeled probe and primer mix and DNA (nt sequences not disclosed). Different combinations of concentrations of the IPC reagents (relative to the manufacturer's recommendation: $1 \times, 0.5 \times$, and $0.25 \times 10 \times$ stock primer/probe mix and $1 \times$ and $0.5 \times$ stock $50 \times$ DNA), Pm components (50 to $800 \mathrm{nM}$ primers; $200 \mathrm{nM}$ probe), and target DNA were assessed for compatibility and best performance (lowest cycle threshold [Ct] value and highest delta normalised reporter $[\Delta \mathrm{Rn}])$.

In the final Pm/IPC duplex-QPCR assay, the $20 \mu \mathrm{l}$ reaction volume comprised $800 \mu \mathrm{M}$ of each $\mathrm{Pm}$ primer, $200 \mu \mathrm{M}$ of $\mathrm{Pm}$ probe, $1.0 \mu \mathrm{l}$ IPC probe/primer mix $(0.5 \times), 0.2 \mu \mathrm{l}$ IPC DNA (0.5×), $10 \mu \mathrm{l}$ TaqMan Universal PCR Master Mix (ABI), $0.5 \mu$ stock BSA (10 $\mathrm{mg} \mathrm{ml}^{-1}$; final concentration of $250 \mathrm{ng} \mathrm{\mu l}^{-1}$; Hallett \& Bartholomew 2006), and $1 \mu$ l DNA template. Reactions were performed in an ABI PRISM 7500 Sequence Detection System in ABI MicroAmp AE optical 96 well reaction plates, with 50 cycles of standard thermal cycling conditions. A positive control (parasite DNA) and a negative control (non-template $=$ molecular grade water) were included in each reaction run. The assay thresholds were set manually at 0.05 for $P m$ and 0.015 for the IPC. All sensitivity and specificity tests used the duplex Pm/IPC QPCR.

Sensitivity and standards: Parasite DNA: Reference standards were prepared of $P m$ actinospores (Fig. 1) 


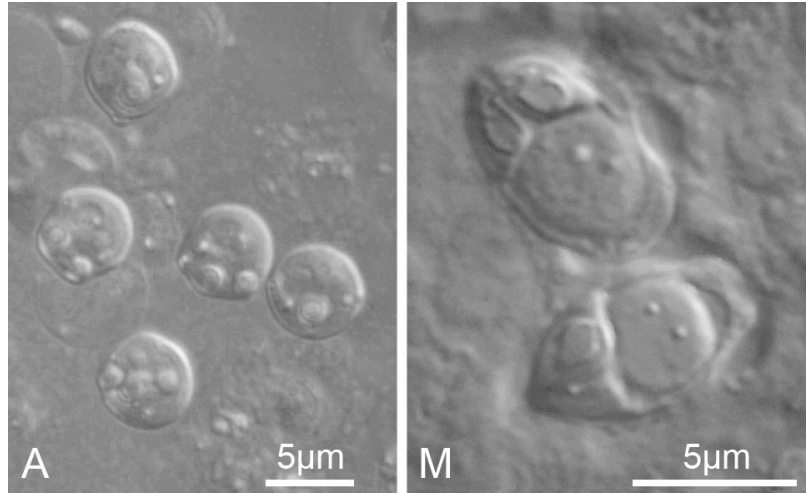

Fig. 1. Parvicapsula minibicornis. Two spore morphotypes in its life cycle; fresh, unstained, viewed under a coverslip with Nomarski interference contrast. The actinospore (A) is released from the polychaete host and infects salmonids, whereas the myxospore $(\mathrm{M})$ is released from the fish host and infects the polychaete

from infected polychaetes Manayunkia speciosa collected from Tree of Heaven (lower Klamath River, California, USA). The host worm was gently squashed under a coverslip to release spores, which, with the aid of a compound microscope (phase contrast and 100x magnification), were transferred using modified glass pipettes onto fractured microscope coverslips and air dried, then added to $2 \mathrm{ml}$ microfuge tubes. Three sets of references were prepared. A single spore was added to a microfuge tube, with dampened filter paper (consistent with field water samples; $\mathrm{n}=4$ ) and without paper $(n=3)$, and $10(n=2)$ spores were added to tubes with paper. These references were processed like the field water samples for direct comparison, and $1 \mu \mathrm{l}$ of sample was run in triplicate in the QPCR. A 10-fold serial dilution series $(n=3)$ was made from the purified DNA of the 1-spore samples processed without paper and $4 \mu \mathrm{l}$ of sample run in triplicate.

Synthetic template: A 10-fold serial dilution of artificial template of the $72 \mathrm{nt} 18 \mathrm{~S}$ ssrRNA target region of the parasite (custom primer from Invitrogen) ranging from 9.62 to $9.62 \times 10^{13}$ copies (35 zg to $3.5 \mu \mathrm{g}$; DNA quantified with a NanoDrop ND-1000 Spectrophotometer) per reaction ( $4 \mu \mathrm{l}$ of sample) was prepared to evaluate the duplex assay. A standard curve of the dilution $\mathrm{Ct}$ values was generated, and the amplification efficiency $(E)$ was estimated by the formula $E=$ $10^{-1 / s}-1$, where $\mathrm{s}$ is the slope of the curve. To determine the influence of the IPC on quantification of our target in the duplex assay, a subset of the synthetic template standards (9.62 to $9.62 \times 10^{6}$ copies) was also assayed in a Pm singleplex assay, which used the duplex assay conditions but with water substituted for the IPC reagents.
Specificity: The assay was tested on other local myxozoans including Ceratomyxa shasta, Myxobolus insidiosus, and M. squamalis, and uninfected salmonid and polychaete host tissue. Fifteen different Parvicapsula minibicornis genetic isolates from a range of hosts (coho, Chinook, sockeye salmon Oncorhynchus nerka, pink salmon O. gorbuscha, and polychaetes) were also assessed.

Field water samples. Collection: Samples were collected along the length of the Klamath River from the Williamson River (easterly headwaters) to below the mouth of the Trinity River (west) to investigate spatial distribution of the parasite and temporal density patterns.

Two sets of water samples were collected in 2006. The first was obtained in coordination with fish sentinel exposures in April (24 to 28), May (15 to 18), June (20 to $23)$, July (18 to 20), and September (12 to 15). Collection sites included 2 upper Klamath River (UKR) sites, viz. the Williamson River tributary (river kilometer [Rkm] 441) and Keno Eddy (Rkm 368), and 5 mainstem lower Klamath River (LKR) sites: R-Ranch (Rkm 292), Beaver Creek (Rkm 258), Seiad Valley (Rkm 207), Saints Rest Bar (Rkm 73), and Tully Creek (Rkm 62; Fig. 2). Triplicate 11 samples were taken manually at the exposure site when fish were placed in the water and approximately $72 \mathrm{~h}$ later when the fish were removed.

The second set of water samples was collected biweekly from March through August at 5 mainstem sites below Iron Gate Dam (LKR): R-Ranch, Beaver Creek, Seiad Valley, Orleans (Rkm 96), and Tully Creek. Samples were also collected monthly at the mouths of 4 tributaries in the LKR: Shasta River (Rkm 284), Scott River (Rkm 229), Salmon River (Rkm 106), and Trinity River (Rkm 71). Triplicate 11 samples were taken at each site.

All samples were transported on ice and then refrigerated until filtration, which occurred within $24 \mathrm{~h}$ of collection.

Filtration and DNA extraction: The water samples were filtered and the retained DNA extracted following the methods described by Hallett \& Bartholomew (2006). Briefly, each 11 sample was filtered through a $5 \mu \mathrm{m}$ cellulose membrane filter (Millipore) using a vacuum pump. Samples containing considerable particulate matter were divided for filtering then recombined during application to the column. The filter disc was folded to fit into a $2.0 \mathrm{ml}$ microfuge tube and frozen prior to being cut into strips and the DNA lysed with $360 \mu \mathrm{l}$ ATL buffer (QIAGEN). Following extraction using the QIAGEN DNeasy Blood and Tissue kit (protocol for animal tissues), the DNA was eluted in $120 \mu \mathrm{l}$ buffer AE. Each field sample was assayed in duplicate, and if the SD of the pair was greater than $1 \mathrm{Ct}$, they were rerun. 


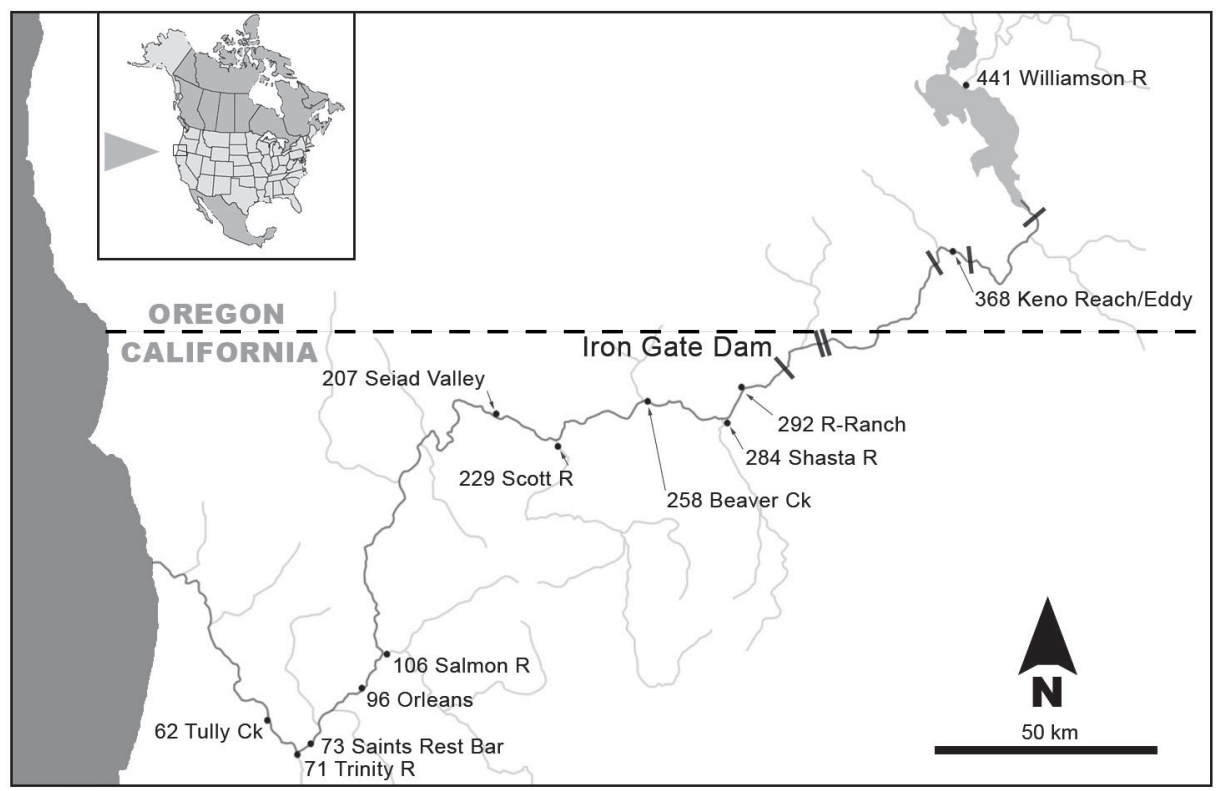

Fig. 2. Klamath River (Oregon, California; USA) showing sites of water collection in 2006. Numbers are river kilometers from mouth (Pacific Ocean). Rectangles represent dams; Iron Gate Dam is impassable to fish and segregates the upper river from the lower. Inset shows location in North America

Assessment and reduction of inhibition: Samples were considered inhibited if their $\mathrm{Ct}$ value was retarded relative to a control, although the color of the sample (amount of particulate matter retained on the filter and subsequent clarity of the extracted DNA) provided an initial indication of the amount of inhibition. Initial spiking tests showed that the degree of inhibition (from none to complete) differed from field site to site, and thus each location had to be assessed at each time point.

In addition to modifying the extraction protocol to include an additional wash with buffer AW2, we investigated 2 other post-extraction/pre-amplification methods to reduce the effects of inhibition: addition of the chemical GeneReleaser (BioVentures; Jiang et al. 2005), and dilution with water. Both required a balance between minimizing inhibition and maximizing parasite DNA such that inhibitors were reduced either through removal or dilution while ensuring that the target DNA was present in sufficient quantity to permit detection ( 1 parasite spore $=1$ infectious unit and provided a positive control). The effectiveness of GeneReleaser was assessed at a range of concentrations and included water as a control. The product was mixed with extracted DNA and the sample incubated, centrifuged, and the 'cleaned' supernatant used in subsequent QPCRs.

Based on these results, 1 of each triplicate water samples from each site was subjected to the duplex QPCR, and all 3 samples were diluted 1:40 if inhibition
(Ct difference between sample and control >2) was indicated. We then used $4 \mu \mathrm{l}$ of the diluted stock DNA eluate in the QPCR. If inhibition remained high $(>2 \mathrm{Ct})$, samples were repurified (see Hallett \& Bartholomew 2006 for details) and rerun.

Data analysis: The final Ct values for field samples were adjusted for both dilution and inhibition for standardization. To adjust for dilution, the $\mathrm{Ct}$ values were reduced by 3 cycles. To adjust for inhibition, the difference in the IPC Ct value between the pure water controls and field water samples was subtracted from the water sample Parvicapsula minibicornis $\mathrm{Ct}$ value. A sample was considered positive if both wells fluoresced in the QPCR, otherwise a Ct value of 42 was designated. The adjusted $\mathrm{Ct}$ values of the triplicate samples collected at each time point and site were averaged and the SD determined. The IPC and a $P$. minibicornis positive control run in quadruplicate on each plate enabled assessment of intra- and inter-plate variation (SD and coefficient of variation, CV). The amount of target DNA (i.e. Pm ssrRNA gene), measured as a $\mathrm{Ct}$ value, was translated to number of parasite spores using reference samples with known quantities of parasite (see above).

Water sample data from June (see Fig. 5) were analyzed using a 1-way analysis of variance (ANOVA; $\mathrm{S}$ Plus 8.0) to determine if there was a significant difference in Ct values between sites, and a Generalized Least Squares analysis compared sites to Beaver Creek. 


\section{RESULTS}

\section{Duplex QPCR assay}

The Pm QPCR primers amplified a product of expected size in the regular PCR. In the duplex assay, $P m$ Ct values did not change substantially with different $\mathrm{Pm}$ primer concentrations (with the exception of the lowest primer concentration, $50 \mathrm{nM}$ ), unlike the $\Delta$ Rn (Table 1); thus the primer concentration with the highest $\Delta \mathrm{Rn}$ was selected for the final assay. The IPC primer and probe mix (used with 1.0× IPC DNA) was more affected by the different $P m$ primer concentrations at $0.25 \times$ than at $0.5 \times$. The only difference in output values in reactions using $1.0 \times$ or $0.5 \times$ IPC DNA was the expected $1 \mathrm{Ct}$. In the final duplex assay, the IPC (all reagents used at $0.5 \mathrm{ABI}$ recommended concentrations) fluoresced at $27 / 28$ cycles when the target $P m$ DNA was present in quantities equal to or less than $\sim 10^{5}$ to $10^{6}$ copies or 3 to $30 \mathrm{fg}$ (Ct 24 to 26 ) of the ssrRNA gene, which would equate to $\sim 1000$ spores (see below). At higher Pm concentrations, the IPC was impaired and fluoresced later. Comparison of the Pm primers and probe in a singleplex and duplex assay indicated slightly better performance in the absence of the IPC (Table 2). Samples in the singleplex fluoresced earlier, and the magnitude of their signal $(\Delta \mathrm{Rn})$ was greater ( 0.5) compared to the duplex. The Ct difference, however, was $<1$, and this was comparable to other sources of intra-assay variation.

The combined Pm/inhibition assay was sensitive enough to detect a single actinospore of Pm: $1 \mu \mathrm{l}$ of extracted DNA (120 $\mu$ l eluate) of single spores coextracted with filter paper fluoresced at 37.1 cycles $(\mathrm{n}=4$; SD 0.4), whereas $1 \mu \mathrm{l}$ of extracted DNA (120 $\mu$ l eluate) from single spores alone fluoresced at 34.7 cycles $(\mathrm{n}=$ 3 ; SD 2.2), indicating a 10-fold loss in DNA caused by
Table 2. Parvicapsula minibicornis. QPCR assay. Comparison of mean (SD) $\mathrm{Ct}$ and $\Delta \mathrm{Rn}$ values for a dilution series of $P m$ artificial template in a singleplex (Pm assay components alone) and duplex (combined $\mathrm{Pm}$ and IPC assay). Samples were run in triplicate. IPC reagents were used at $0.5 \times$. NC: negative control contained molecular grade water; ud: Ct undetected within 50 cycles

\begin{tabular}{|lccc|}
\hline Sample & $\begin{array}{c}\text { Singleplex } \\
\text { Pm }\end{array}$ & $\begin{array}{c}\text { Duplex } \\
\text { Pm }\end{array}$ & $\begin{array}{c}\text { Duplex } \\
\text { IPC }\end{array}$ \\
\hline Ct & & & \\
Pm10 & $20.1(0.1)$ & $20.4(0.0)$ & $32.9(0.4)$ \\
Pm10 & $24.2(0.1)$ & $24.5(0.2)$ & $31.1(0.4)$ \\
Pm10 & $27.5(0.2)$ & $28.0(0.0)$ & $31.0(0.2)$ \\
Pm10 & $31.2(0.1)$ & $31.5(0.1)$ & $31.0(0.0)$ \\
Pm10 & $34.6(0.4)$ & $35.2(0.2)$ & $31.0(0.1)$ \\
Pm10 & $37.8(0.4)$ & $37.8(0.2)$ & $31.1(0.2)$ \\
Pm10 & ud & ud & $31.0(0.1)$ \\
NC & ud & ud & $31.0(0.2)$ \\
$\Delta$ Rn & & & \\
Pm10 & $2.5(0.0)$ & $1.9(0.0)$ & $0.2(0.0)$ \\
Pm10 & $2.4(0.0)$ & $1.9(0.0)$ & $0.2(0.0)$ \\
Pm10 & $2.4(0.0)$ & $1.9(0.0)$ & $0.2(0.0)$ \\
Pm10 & $2.2(0.0)$ & $1.8(0.0)$ & $0.2(0.0)$ \\
Pm10 & $2.1(0.2)$ & $1.7(0.1)$ & $0.2(0.0)$ \\
Pm10 & $2.0(0.1)$ & $1.6(0.3)$ & $0.2(0.0)$ \\
Pm10 & $0.0(0.0)$ & $0.0(0.0)$ & $0.2(0.0)$ \\
NC & $0.0(0.0)$ & $0.0(0.0)$ & $0.2(0.0)$ \\
\hline
\end{tabular}

the necessary filtration method for environmental samples. The 10 spore samples with filter paper fluoresced at $34.1(\mathrm{n}=2$; $\mathrm{SD} 0)$.

A dilution series of the single spore samples showed that the detection limit of the assay (i.e. not all 3 wells of a sample fluoresced beyond this point) is about 40 cycles. A similar threshold presented for the synthetic template series. The assay could detect 96.2 copies (3.5 ag) of the ssrRNA gene (i.e. all 3 wells fluoresced)

Table 1. Parvicapsula minibicornis (Pm). Pm/IPC (internal positive control) duplex QPCR optimization: assessment (mean [SD] $\mathrm{Ct}$ and $\Delta \mathrm{Rn}$ ) of different Pm primer and IPC concentrations. The concentration of the Pm probe was a constant $200 \mathrm{nM}$. Samples were run in duplicate. A low target template sample that would be more sensitive to assay changes was used as the source of Pm. IPC DNA was used at 1.0 strength. The final assay used the combination with lowest Ct and highest $\Delta \mathrm{Rn}$ (in bold): $800 \mathrm{nM}$ $P m$ primers and $0.5 \times$ IPC

\begin{tabular}{|c|c|c|c|c|c|c|c|c|}
\hline \multirow{2}{*}{$\begin{array}{l}\text { Pm primer } \\
\text { concentration } \\
\text { (nM) }\end{array}$} & \multicolumn{4}{|c|}{$-0.5 \times \mathrm{IPC} \longrightarrow$} & \multicolumn{4}{|c|}{$0.25 \times \mathrm{IPC}$} \\
\hline & $P m$ & IPC & $\overline{P m}$ & $n \overline{\text { IPC }}$ & $P m$ & IPC & $\overline{P m} \Delta \mathrm{l}$ & $n \overline{\text { IPC }}$ \\
\hline 800 & $33.7(0.5)$ & $25.5(0.0)$ & $1.5(0.0)$ & $0.2(0.0)$ & $33.6(0.2)$ & $31.5(0.4)$ & $1.4(0.1)$ & $0.1(0.0)$ \\
\hline 600 & $34.0(0.1)$ & $25.3(0.1)$ & $1.3(0.0)$ & $0.2(0.0)$ & $33.6(0.4)$ & $30.8(0.4)$ & $1.5(0.0)$ & $0.1(0.0)$ \\
\hline 400 & $34.3(0.2)$ & $25.4(0.2)$ & $1.2(0.0)$ & $0.2(0.0)$ & $34.0(0.1)$ & $30.3(0.3)$ & $1.4(0.0)$ & $0.1(0.0)$ \\
\hline 300 & $34.4(0.1)$ & $25.4(0.2)$ & $1.1(0.0)$ & $0.2(0.0)$ & $34.1(0.2)$ & $30.0(0.8)$ & $1.3(0.0)$ & $0.1(0.0)$ \\
\hline 150 & $36.0(0.1)$ & $25.8(0.1)$ & $0.8(0.0)$ & $0.2(0.0)$ & $36.2(0.1)$ & $29.8(0.4)$ & $0.9(0.0)$ & $0.1(0.0)$ \\
\hline 50 & $44.1(1.4)$ & $25.8(0.1)$ & $0.2(0.1)$ & $0.2(0.0)$ & $35.6(0.9)$ & $30.1(0.2)$ & $1.1(0.2)$ & $0.1(0.0)$ \\
\hline
\end{tabular}


but not as few as 9.62 copies (i.e. not all 3 wells fluoresced).

The detection threshold in the serial dilution series of the 1 -spore samples averaged $1.6 \times 10^{-4}$ spores, which indicated that each spore had approximately $1.6 \times 10^{4}$ copies of the ssrRNA gene. An alternative method to derive copy numbers, comparing $\mathrm{Ct}$ values from the 1spore samples to those of the artificial template whose copy numbers are known, indicated that 1 spore had approximately $3.5 \times 10^{4}$ copies of the gene.

The standard curve generated from 10-fold serial dilutions of the artificial template was linear over 9 logs from 9.62 to $9.62 \times 10^{10}$ copies (mean Ct 38.5 and 3.0, respectively; Fig. 3). The slope of the curve was -4.0257 , with a $y$-intercept of 44.694 and squared correlation coefficient $\left(\mathrm{R}^{2}\right)$ of 0.9994 . The amplification efficiency was $77.2 \%$.

The assay was specific for Parvicapsula minibicornis, and all genetic isolates fluoresced with $\Delta \mathrm{Rn}$ values consistent with the standards.

\section{Field water samples}

Inhibition

A ratio of sample to GeneReleaser of 1:6 was most effective at reducing inhibition; however, this concentration affected detection of the IPC. Dilution of the eluted DNA with water proved most effective. In either set of water samples, most (96\%) showed some degree of inhibition; $51 \%$ varied from the control by $<1 \mathrm{Ct}$, whereas 13 to $15 \%$ were $>2 \mathrm{Ct}$ higher. April had the most samples with the most inhibition. Dilution reduced the amount of inhibition, but samples would usually still register low inhibition.

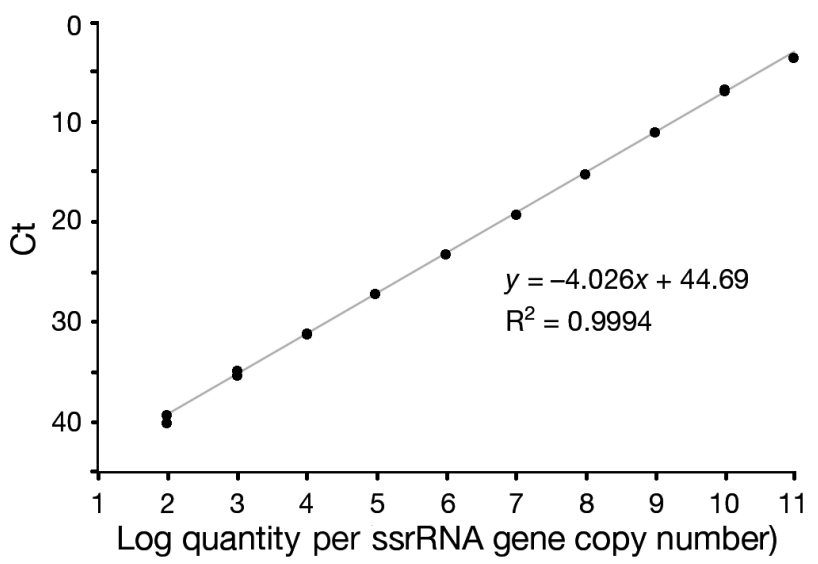

Fig. 3. Parvicapsula minibicornis. Standard curve derived from 10-fold serial dilutions of synthetic ssrRNA template in the duplex P. minibicornis/IPC QPCR assay
Assay variation

The intra-assay variation assessed for 6 plates ranged from 0.2 to $1.7 \mathrm{SD}$ and 0.7 to $5.1 \% \mathrm{CV}$ for the $P m$ control and 0.1 to $0.3 \mathrm{SD}$ and 0.3 to $1.0 \% \mathrm{CV}$ for the IPC. Inter-plate variation was $1.1 \mathrm{SD}$ and $3.4 \% \mathrm{CV}$ for $\mathrm{Pm}$ and $0.2 \mathrm{SD}$ and $0.7 \% \mathrm{CV}$ for the IPC. The interplate mean Ct for Pm was 32.5 and for the IPC 27.5.

Parasite abundance and distribution

Parvicapsula minibicornis was detected at all Klamath River mainstem sites tested (Fig. 4). Of the sites sampled in March, none tested positive ( $\geq 1$ spore $1^{-1}$ ) until spring. At most sites, spore abundance increased from March to June/July from 1 spore $\mathrm{l}^{-1}$ to as high as $\sim 100$ spores $\mathrm{l}^{-1}$ at Williamson River, Beaver Creek, and Seiad Valley. At the latter 2 sites, prevalence clearly decreased thereafter; however, at the remaining sites a pattern was not clear. Unlike any other site, relatively high levels of parasite (10 to 100 spores $1^{-1}$ ) were sustained at Williamson River throughout the collection period. There was little variation in parasite abundance between sites at the beginning of spring (March/April), but this became pronounced in June with densities varying by 2 orders of magnitude (Fig. 5). A 1-way ANOVA indicated that differences in parasite levels in June were significant $(F=15.03, \mathrm{df}=7, \mathrm{p}<0.0001)$. A Generalized Least Squares analysis comparing the $\mathrm{Ct}$ values of sites to Beaver Creek indicated that 5 of the 7 differed significantly; Seiad Valley and the Williamson River were not significantly different $(p=0.3525$ and 0.1077 , respectively). The greatest variation among site triplicates occurred when the parasite was present in low levels (high Ct values) and/or 1 or more samples was negative (and designated Ct 42).

The parasite was only present in low numbers (1 spore $\mathrm{l}^{-1}$ or less) in most tributary samples (data not shown). The exceptions were the Trinity River in the LKR, which on 3 occasions (in March, June, and August) had $>1$ to $<10$ spores $1^{-1}$ and the Williamson River in the UKR, which consistently had parasite abundance $>10$ spores $1^{-1}$ (Fig. 4).

The 2 water sample sets, sentinel and biweekly, rarely overlapped. They shared 4 LKR sites, R-Ranch, Beaver Creek, Seiad Valley, and Tully Creek, but only 1 time point, 20 June. The data presented a similar pattern, except at Tully Creek (Fig. 5).

\section{DISCUSSION}

\section{Duplex QPCR assay}

True et al. (2009) developed a singleplex QPCR assay to detect the myxozoan Parvicapsula minibicor- 


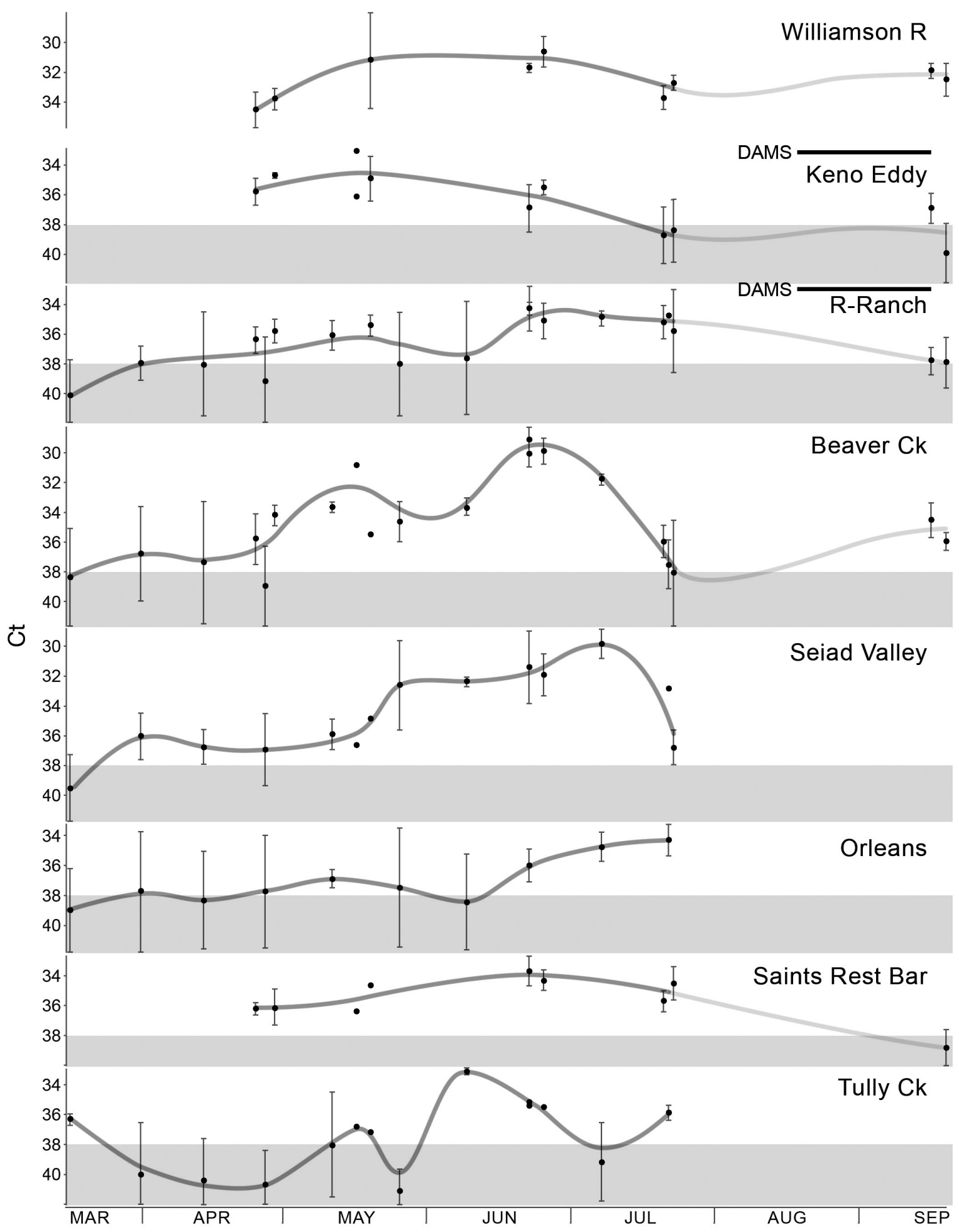

Fig. 4. Parvicapsula minibicornis. Distribution and abundance at 8 sites in the Klamath River from the headwaters at Williamson River to Tully Creek in the lower river as determined from QPCR detection of DNA in water samples (biweekly and sentinel) collected from March through September 2006. Rectangles represent dams; Iron Gate Dam blocks fish passage and separates the 2 upper Klamath River sites from the remainder in the lower Klamath River. Each data point is the mean of three 11 samples and error bars are $\pm 1 \mathrm{SD}$ (at 2 time points in May, the 3 samples were inadvertently combined during processing and there is no error bar). The cycle threshold $(\mathrm{Ct})$ is displayed on the $y$-axis; lower $\mathrm{Ct}$ values indicate that more parasite DNA is present. Shaded region: $<1$ actinospore $1^{-1}$ 


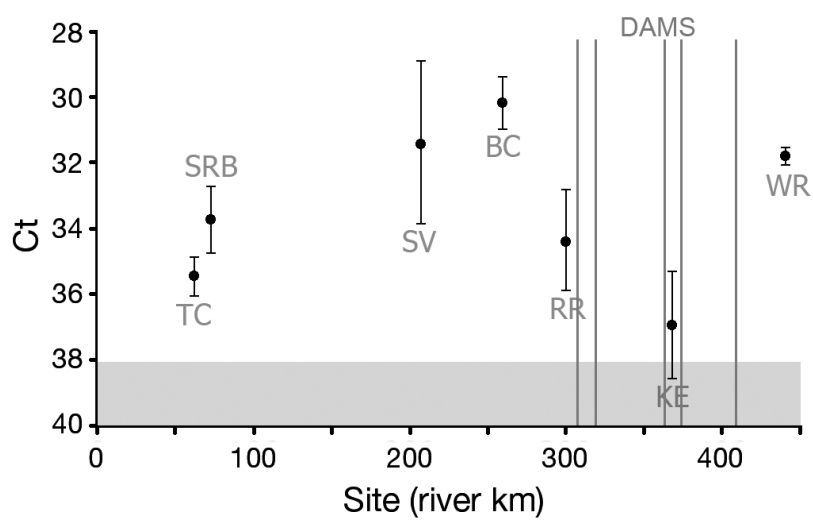

Fig. 5. Parvicapsula minibicornis. Abundance (QPCR detection of DNA) in water samples collected on 20 June 2006 from mainstem Klamath River sites and the Williamson River headwater. The greatest spatial variation in the river was observed this month. Each data point is the mean of three $1 \mathrm{l}$ water samples and error bars are $\pm 1 \mathrm{SD}$. Lower $\mathrm{Ct}$ values indicate that more parasite DNA is present; a difference of $\sim 3.3 \mathrm{Ct}$ equals a 10-fold difference in DNA. Shaded region: $<1$ actinospore $1^{-1}$. Grey lines denote dams and the division of upper and lower Klamath River. WR: Williamson River, KE: Keno Eddy, RR: RRanch, BC: Beaver Creek, SV: Seiad Valley, SRB: Saints Rest Bar, TC: Tully Creek

nis in fish tissue, and Bartholomew et al. (2007) applied the assay to river water samples to quantify waterborne stages of the parasite. Here we report development of a duplex QPCR to detect the different genetic strains of P. minibicornis (Atkinson et al. 2007) and concurrently test for assay inhibition.

An initial objective was to develop a triplex QPCR to simultaneously detect Ceratomyxa shasta and Parvicapsula minibicornis, the 2 most prevalent myxozoan parasites present in the Klamath River, as well as to test for inhibition in the water samples and thereby reduce processing efforts and costs. However, because such an assay would be qualitative rather than quantitative at the low concentrations $\left(1\right.$ spore $\left.^{-1}\right)$ in water samples (P. Grass \& B. Whitmire pers. comm.), we focused on a duplex assay: either C. shasta/P. minibicornis, C. shasta/inhibition (IPC), or P. minibicornis/ inhibition. We assessed all 3 combinations, adjusting primer and DNA concentrations (data not shown). Initial compatibility trials showed that the C. shasta primers and probe were incompatible with those of either the IPC or P. minibicornis. Only the P. minibicornis/inhibition assay performed equally well in duplex as in singleplex, and specificity and sensitivity trials continued with this combination.

Inhibitors present in environmental water samples can interfere with the QPCR and give inaccurate values for the target organism. Previously, to test for PCR inhibition and distinguish false negatives from true target negatives, we spiked a duplicate set of water sam- ples with low concentrations of target DNA (Hallett \& Bartholomew 2006); any variation from the reference $\mathrm{Ct}$ suggested the presence of inhibitors (Bustin \& Nolan 2004). Incorporating an IPC in a duplex QPCR enabled indirect but concurrent testing of samples for inhibition.

Other researchers have used an IPC similarly, but did not describe how their sample final Ct values were adjusted to reflect any detected inhibition (McBeath et al. 2006, Swango et al. 2006, Behets et al. 2007); in most cases, inhibited samples in these studies were diluted and rerun. We compared the IPC Ct values of our field samples to laboratory controls and adjusted the final sample Ct value for low levels of inhibition. Samples exhibiting high levels of inhibition (Ct difference $>2$ ) were further processed and rerun. Our lab trials demonstrated that high concentrations of the target organism $(<\mathrm{Ct} 26)$ also retarded the IPC Ct values, but none of the field samples fluoresced earlier than $\mathrm{Ct} 28$ (equivalent to $>100$ spores $\mathrm{l}^{-1}$ ); thus we attributed any change in IPC Ct value to non-target inhibition.

The IPC used a different set of primers and probe than Parvicapsula minibicornis and thus provided an indication of inhibition rather than an exact measure, but enabled adjustment of sample Ct values to better reflect the real parasite abundance and allow sample comparisons. To avoid the amplification of the IPC target at the expense of $P$. minibicornis, we halved the manufacturer's recommendation for its primer and probe concentration. We also reduced the IPC template to render it more susceptible to adverse assay conditions and better mimic the target; normally, a quantity of IPC template would be used that ensures amplification even in the presence of large amounts of the target of interest or inhibitors (Phillips 2004). In our assessment of the IPC, we checked that the level of inhibition was altered by the concentration of the sample, and that the final adjusted $\mathrm{Ct}$ values of a set of field replicates were approximately equal irrespective of treatment. Repurification of all samples that showed any level of inhibition would be too costly. Dilution was the best alternative, although in some cases the inhibition could not be sufficiently diluted without also codiluting the parasite beyond its detection level. In these cases, the sample would be re-purified.

The IPC from ABI is pre-optimized, but we further limited the concentration of the IPC reagents in the duplex assay to avoid compromising the amplification efficiency of the target reaction since the target and IPC DNA templates likely differ in concentration. The amplification efficiency of the duplex QPCR was low $(77.2 \%)$, but we were restricted in our choice of primers and probe to an ssrRNA sequence region conserved among the Parvicapsula minibicornis isolates but which differed from other species. We were never- 
theless able to detect the smallest theoretical infectious unit (1 spore) in a 11 water sample. This sensitivity is likely by virtue of the high number of copies of the ssrRNA gene in each spore. We estimated $10^{4}$ copies, 10 -fold more than suggested by the data in True et al. (2009). This discrepancy may be resolved by increasing the number of single spore replicates analyzed as well as by using unextracted spores directly in the duplex assay.

To develop standard curves, it is recommended to amplify standards and unknowns from the same source of DNA (Bustin 2004), but obtaining high spore counts (i.e. 100) of either life cycle stage of Parvicapsula minibicornis is problematic. The parasite cannot be cultured, and while the prevalence of infection in the fish host is high (Bartholomew et al. 2007), it is rare to find mature myxospores as they are apparently excreted upon formation (Bartholomew et al. 2006). In contrast, numerous mature actinospores can be identified within the polychaete host, but the natural prevalence is low (Bartholomew et al. 2007) plus development of the actinospore is asynchronous and other stages are also present within the host (Bartholomew et al. 2006). Thus, although we were able to translate $\mathrm{Ct}$ values into numbers of spores based on low numbers of individually collected spores, we also used synthetic template, which was available in high concentrations suitable for performing serial dilution series and associated standard curves, to evaluate assay performance.

\section{Parasite spatial and temporal distribution in the Klamath River}

Real-time or quantitative PCR analysis of water samples provides data on the distribution and abundance of specific pathogens independent of their hosts. Assays have now been developed for a range of important human, fish, and shellfish aquatic pathogens from protozoans to crustaceans (see Guy et al. 2003, Haugland et al. 2005, Audemard et al. 2006, Hallett \& Bartholomew 2006, McBeath et al. 2006). We used a duplex QPCR assay to map the occurrence of Parvicapsula minibicornis in the Klamath River in 2006.

This study is part of ongoing investigations conducted by multiple agencies researching the epidemiology of salmonid diseases in the Klamath River with the goal of developing a baseline model that addresses factors regarding fish health. It expands on the data of Bartholomew et al. (2007), who reported the riverine spatial distribution of Parvicapsula minibicornis at only 1 time point (June 2004), and that of Foott et al. (2007), who reported the temporal distribution (over $3 \mathrm{mo}$ ) at only 1 river locale, whereas herein we examined both spatial and temporal distribution and abundance of the parasite over 7 mo (March through September 2006) throughout the river basin.

We detected the parasite throughout the Klamath mainstem with levels indicative of as high as 100 spores $\mathrm{l}^{-1}$ at some sites. In contrast to the UKR headwater tributary (Williamson River), the 4 LKR tributaries sampled did not contribute significant parasite numbers to the mainstem (generally $<1$ spore $\mathrm{l}^{-1}$ river water). Highest levels $\left(>1<10\right.$ spores $\left.l^{-1}\right)$ were detected in water samples from the Trinity River, and this was the only tributary examined in which infected fish were identified by Bartholomew et al. (2007).

The spatial trend of Parvicapsula minibicornis was consistent between June 2004 (Bartholomew et al. 2007) and 2006, with the Williamson River and the river reach between Beaver Creek and Seiad Valley being a zone of high abundance in both years. In the upper basin, the spatial distribution of the parasite below the Williamson River is unknown; only low levels were detected at Keno Eddy, the only other site sampled here. A pattern was evident in the LKR. Parasite levels were low in the $20 \mathrm{Rkm}$ below Iron Gate Dam, then increased at approximately the confluence with the Shasta River for about $70 \mathrm{Rkm}$, decreasing again downstream of Seiad Valley. Combined with the prevalence of infection in polychaetes (Bartholomew et al. 2007), these data suggest that parasite distribution is likely affected by dilution relative to distance from its source of release, and little local input from tributaries. Actinospores released from infected polychaetes are the likely source of the parasite from May through August, with myxospores from adult fish contributing in the months of September through January as they return to spawn.

There were seasonal differences in abundance of Parvicapsula minibicornis, with release beginning in late March and peaking in late June to mid-July. At sites where parasite levels were high, abundance clearly decreased by late July. However, the lack of data for August and the inability to distinguish myxospores from actinospores make it difficult to determine if a second peak of release occurs in the fall (September).

The Williamson River differed from the majority of sites sampled in not having a distinct peak in abundance, as parasite levels remained relatively high throughout the collection period. This likely reflects the different infection dynamics in this part of the basin, which is physically segregated from the LKR by a series of dams that block the passage of anadromous salmonids (Fig. 2). Thus the infectious cycle in the upper basin is apparently maintained in the resident redband rainbow trout or stocked hatchery rainbow trout (Bartholomew et al. 2007). 
The water sampling findings in the LKR were consistent with observance of the parasite in its fish host in other studies. Three main species of LKR anadromous salmonids, Chinook and coho salmon and steelhead, are susceptible to Parvicapsula minibicornis (Bartholomew et al. 2007, Nichols \& True 2007, Stone et al. 2008). The first detection of the parasite in water samples coincided with the emergence of these salmonid fry in the spring. Juveniles then migrate downstream in spring and summer, depending on the species, and hatchery stocks are released into the mainstem at this time. Whereas fall Chinook salmon steadily move downstream throughout the summer, spring Chinook may reside in streams for 1 yr or more before they move to the ocean, coho salmon spend the first 14 to 18 mo in fresh water, and winter steelhead may spend between 1 and 3 yr in fresh water (National Research Council 2004). Peak parasite abundances in water samples from late spring/early summer overlapped with the migration period but were not consecutive with $\mathrm{Rkm}$. The first detections in migrating juvenile salmon in 2006 were in mid-March and peaked in midJuly, a pattern that was delayed in comparison to previous years (Nichols \& True 2007). Recovery of a tagged sub-population of juvenile Chinook salmon released from just below Iron Gate Dam in 2006 showed that 2 wk after hatchery release, over $60 \%$ of these fish were infected with $P$. minibicornis, and by $3 \mathrm{wk}, 100 \%$ were infected (Nichols \& True 2007). The prevalence of infection in unmarked migrants captured at the Shasta River confluence was high, indicating that the infectious zone extends upriver of Beaver Creek.

Chinook and steelhead juveniles may persist in mainstem pools throughout summer, whereas coho are uncommon (National Research Council 2004). Despite residing the least in the mainstem, coho still experienced a Parvicapsula minibicornis incidence of $59 \%$ (Nichols \& True 2007).

Adult spring Chinook reenter the LKR the earliest, in April through July, and aggregate in deep pools for 2 to 4 mo before spawning, whereas the other stocks return in the fall and spawn (National Research Council 2004). Parvicapsula minibicornis prevalences ranging from 55 to $100 \%$ have been recorded in returning hatchery stocks (Bartholomew et al. 2007). More direct comparisons of parasite abundance and infection of fish could have been drawn from our sentinel studies, but unfortunately molecular assessment of 'unexposed' control fish indicated that they had become infected at their rearing source (hatchery), prior to the intentional river exposure of their cohort.

Data from analysis of water samples show that, despite sharing both its vertebrate and invertebrate host with another myxozoan parasite, Ceratomyxa shasta, Parvicapsula minibicornis has a slightly different temporal and spatial distribution. The 'hot spots' for both parasites were the same; however, $P$. minibicornis was present earlier in the year (low numbers in March 2006 [spring]), in greater numbers, and at more sites. The similar overall distribution suggests that the parasites are maintained by relatively high numbers of infected polychaetes in the Williamson River in the UKR and above Beaver Creek in the LKR. One reason for the higher abundance of $P$. minibicornis in comparison to $C$. shasta may be its replication rate in the polychaete host. Polychaetes infected by $P$. minibicornis were observed to harbor at least an order of magnitude more parasites than those infected by C. shasta, likely a result of their smaller spore size and development location (Bartholomew et al. 2006). Another factor that may contribute to the observed broader distribution of P. minibicornis is its mechanism of release from the salmonid host. Myxospores of this parasite are shed in the urine of infected fish and thus may be broadcast more widely than C. shasta, which is most likely released in high numbers upon death of the fish host at specific locations (e.g. adult spawning grounds).

Parvicapsula minibicornis appears endemic to fresh waters of the Pacific Northwest of North America and thus there is potential for negative impacts on salmonid fishes throughout its range. First reported from the Fraser River in British Columbia, Canada (Kent et al. 1997), it is now known from as far south as the Sacramento River in California (K. Nichols pers. comm.). Whereas adult sockeye salmon are reported to be most severely affected by the parasite in the northern extent of this range (Jones et al. 2003), in the Klamath River severe infections occur in juvenile Chinook salmon (Bartholomew et al. 2007, Nichols \& True 2007, Stone et al. 2008). However, the prognosis of infection in juvenile fish is unknown, and they may recover if they survive the anemia and osmoregulatory problems related to the glomerulonephritis associated with the infection (Nichols \& True 2007).

QPCR assessment of water samples offers a faster, more cost-effective means of detecting parasites than using sentinel fish, and is more sensitive than conventional PCR. However, the assay cannot distinguish between the 2 spore stages (actinospore and myxospore) in the parasite's life cycle or between infective and dead organisms. Furthermore, as highlighted above, the assay is subject to inhibition. Altogether, it provides a means for rapid evaluation of parasite levels and correlation of these with changes in river conditions. In 2006, river flows during April, May, and June were higher than average; thus the data presented here provide a baseline for comparison. We plan to extend the field season and collect samples throughout the year to map annual fluctuations in abundance. Fur- 
ther research linking these parasite levels to biological effects on Chinook and coho salmon should allow estimates of mortality and the opportunity for immediate management responses.

Acknowledgements. We thank the following people for their contribution. The Karuk and Yurok tribes of California, R. Stocking, and R. Holt (OSU) assisted with water sample collection and filtration. S. Corum (Karuk Tribe) assisted with site selection and coordination of sampling. G. Cobarrubias (OSU) extracted and assayed the field water samples. J. Dubanoski (OSU) assisted with QPCR. S. Atkinson prepared the reference spore samples, supplied the Parvicapsula minibicornis genetic isolates' sequence data and DNA samples, and assisted with figure preparation. C. Banner (Oregon Department of Fish and Wildlife) provided the Myxobolus insidiosus and $M$. squamalis samples. A. Ray (OSU) performed the statistical analyses. Applied Biosystems representatives B. Whitmire and P. Grass provided technical advice. J. Wood of Pisces Molecular advised on GeneReleaser. The Central Service Laboratory in the Center for Gene Research and Biotechnology, OSU, provided the QPCR machine and NanoDrop Spectrophotometer. K. True and K. Nichols reviewed an earlier version of the manuscript. This publication was partially supported by the National Sea Grant College Program of the US Department of Commerce's National Oceanic and Atmospheric Administration under NOAA Grant \# NA16RG1039 (project number R/RCF-15) and by appropriations made by the Oregon State legislature. Support was also provided by the US Fish and Wildlife Service, via the Klamath River Basin Fisheries Task Force, the Karuk Tribal Fisheries Program, and PacifiCorp. The views expressed herein do not necessarily reflect the views of any of those organizations.

\section{LITERATURE CITED}

Atkinson SD, Jones SMR, Bartholomew JL (2007) Parvicapsula minibicornis: a myxozoan species complex? In: Coluzzi M (ed) Parassitologia. 7th Int Symp Fish Parasites. Lombardo Editore, Rome, p 139

Audemard C, Reece KS, Burreson EM (2004) Real-time PCR for detection and quantification of the protistan parasite Perkinsus marinus in environmental waters. Appl Environ Microbiol 70:6611-6618

Audemard C, Ragone Calvo LM, Paynter KT, Reece KS, Burreson EM (2006) Real-time PCR investigation of parasite ecology: in situ determination of oyster parasite Perkinsus marinus transmission dynamics in lower Chesapeake Bay. Parasitology 132:827-842

Bartholomew JL, Rohovec JS, Fryer JL (1989) Ceratomyxa shasta, a myxosporean parasite of salmonids. Fish Disease Leaflet 80, US Fish and Wildlife Service

Bartholomew JL, Whipple MJ, Stevens DG, Fryer JL (1997) The life cycle of Ceratomyxa shasta, a myxosporean parasite of salmonids, requires a freshwater polychaete as an alternate host. J Parasitol 83:859-868

Bartholomew JL, Atkinson SD, Hallett SL (2006) Involvement of Manayunkia speciosa (Annelida: Polychaeta: Sabellidae) in the life cycle of Parvicapsula minibicornis, a myxozoan parasite of Pacific salmon. J Parasitol 92:742-748

Bartholomew JL, Atkinson SD, Hallett SL, Zielinski CM, Foott JS (2007) Distribution and abundance of the salmonid parasite Parvicapsula minibicornis (Myxozoa) in the Klamath
River Basin (Oregon-California, USA). Dis Aquat Org 78:137-146

Behets J, Declerck P, Delaedt Y, Verelst L, Ollevier F (2007) A duplex real-time PCR assay for the quantitative detection of Naegleria fowleri in water samples. Water Res 41: 118-126

Bustin SA (ed) (2004) A-Z of quantitative PCR. International University Line, La Jolla, CA

Bustin SA, Nolan T (2004) Data analysis and interpretation. In: Bustin, SA (ed) (2004) A-Z of quantitative PCR. International University Line, La Jolla, CA, p 439-492

Conrad JF, Decew M (1966) First report of Ceratomyxa in juvenile salmonids in Oregon. Prog Fish-Cult 28:238

Foott JS, Harmon R, Stone R (2004a) FY2003 investigational report: abundance of Ceratomyxa shasta in Iron Gate and Copco Reservoirs. US Fish and Wildlife Service CaliforniaNevada Fish Health Center, Anderson, CA

Foott JS, Harmon R, Stone R (2004b) Effect of water temperature on non-specific immune function and ceratomyxosis in juvenile Chinook salmon and steelhead from the Klamath River. Calif Fish Game 90:71-84

Foott JS, Stone R, Wiseman E, True K, Nichols K (2007) Longevity of Ceratomyxa shasta and Parvicapsula minibicornis actinospore infectivity in the Klamath River. J Aquat Anim Health 19:77-83

Guy RA, Payment P, Krull UJ, Horgen PA (2003) Real-time PCR for quantification of Giardia and Cryptosporidium in environmental water samples and sewage. Appl Environ Microbiol 69:5178-5185

> Hallett SL, Bartholomew JL (2006) Application of a real-time PCR assay to detect and quantify the myxozoan parasite Ceratomyxa shasta in river water samples. Dis Aquat Org 71:109-118

> Haugland RA, Siefring SC, Wymer LJ, Brenner KP, Dufour AP (2005) Comparison of Enterococcus measurements in freshwater at two recreational beaches by quantitative polymerase chain reaction and membrane filter culture analysis. Water Res 39:559-568

> Jiang J, Alderisio KA, Singh A, Xiao L (2005) Development of procedures for direct extraction of Cryptosporidium DNA from water concentrates and for relief of PCR inhibitors. Appl Environ Microbiol 71:1135-1141

> Jones SRM, Prosperi-Porta G, Dawe SC, Barnes DP (2003) Distribution, prevalence, and severity of Parvicapsula minibicornis infections among anadromous salmonids in the Fraser River, British Columbia, Canada. Dis Aquat Org 54:49-52

- Kent ML, Whitaker DJ, Dawe SC (1997) Parvicapsula minibicornis n. sp. (Myxozoa, Myxosporea) from the kidney of sockeye salmon (Oncorhynchus nerka) from British Columbia, Canada. J Parasitol 83:1153-1156

> McBeath AJA, Penston MJ, Snow M, Cook PF, Bricknell IR, Cunningham CO (2006) Development and application of real-time PCR for specific detection of Lepeophtheirus salmonis and Caligus elongatus larvae in Scottish plankton samples. Dis Aquat Org 73:141-150

National Research Council (2004) Endangered and threatened fish in the Klamath River basin: causes of decline and strategies for recovery. The National Academies Press, Washington, DC

Nichols K, Foott JS (2006) FY2004 investigational report: health monitoring of juvenile Klamath River Chinook salmon. US Fish \& Wildlife Service California-Nevada Fish Health Center, Anderson, CA

Nichols K, True K (2007) FY 2006 investigational report: monitoring incidence and severity of Ceratomyxa shasta and Parvicapsula minibicornis infections in juvenile Chinook 
salmon (Oncorhynchus tshawytscha) and coho salmon (Oncorhynchus kisutch) in the Klamath River, 2006. US Fish \& Wildlife Service California-Nevada Fish Health Center, Anderson, CA

Nichols K, True K, Wiseman E, Foott JS (2007) FY2005 investigational report: incidence of Ceratomyxa shasta and Parvicapsula minibicornis infections by QPCR and histology in juvenile Klamath River Chinook salmon. US Fish \& Wildlife Service California-Nevada Fish Health Center, Anderson, CA

Phillips JM (2004) Real-time RT-PCR: what lies beneath the surface. In: Bustin SA (ed) A-Z of quantitative PCR. International University Line, La Jolla, CA, p 47-85

Schafer WE (1968) Studies on the epizootiology of the myxosporidian Ceratomyxa shasta Noble. Calif Fish Game 54: 90-99

St-Hilaire S, Boichuk M, Barnes D, Higgins M and others (2002) Epizootiology of Parvicapsula minibicornis in Fraser River sockeye salmon, Oncorhynchus nerka (Walbaum). J Fish Dis 25:107-120

Editorial responsibility: David Marcogliese, Montreal, Quebec, Canada
Stocking RW, Holt RA, Foott JS, Bartholomew JL (2006) Spatial and temporal occurrence of the salmonid parasite Ceratomyxa shasta (Myxozoa) in the Oregon-California Klamath River basin. J Aquat Anim Health 18:194-202

Stone R, Foott JS, Fogerty R (2008) FY2006 investigational report: comparative susceptibility to infection and disease from Ceratomyxa shasta and Parvicapsula minibicornis in Klamath River basin juvenile Chinook, coho, and steelhead populations. US Fish \& Wildlife Service CaliforniaNevada Fish Health Center, Anderson, CA

Swango KL, Timken MD, Chong MD, Buoncristiani MR (2006) A quantitative PCR assay for the assessment of DNA degradation in forensic samples. Forensic Sci Int 158:14-26

True K, Purcell M, Foott JS (2009) Development and validation of a quantitative PCR to detect Parvicapsula minibicornis and comparison to histologically ranked infection of juvenile Chinook salmon, Oncorhynchus tshawytscha (Walbaum), from the Klamath River, USA. J Fish Dis 32:183-192

Submitted: August 13, 2008; Accepted: June 22, 2009 Proofs received from author(s): August 31, 2009 